\title{
STUDIES ON PATHOGENICITY OF ESCHERICHIA COLI AN OBSERVATION ON VIRULENCE* OF ESCHERICHIA COLI FOR MICE TREATED WITH WETTING AGENT
}

\author{
SHIGEO NAMIOKA, MASAYOSHI MURATA \\ 1st Section of Bacteriology, 1st Department of Research, \\ National Institute of Animal Health, Kodaira, Tokyo \\ AND RIICHI SAKAZAKI \\ Department of Bacteriology I, National Institute of Health, Tokyo
}

(Received: February 11th, 1961)

Pathogenic behavior of Escherichia coli has been explored with regard to necrotizing power, hemolysis, toxicity for mice, and other characteristics. On the other hand, the presence of certain pathogenic Escherichia culture has been clarified by serological investigation. However, when a culture of Escherichia coli, the sero-type of which is different from that of any known pathogenic organism, is isolated from gastro-enteritis, it is very difficult to determine whether the culture is the causative agent of the disease or not.

Sjöstedt (1946) found that Escherichia cultures belonging to certain 0 groups (2, 4, and 6) were frequently hemolytic, confirming Ewertsen's finding (1946) that hemolysis and the capacity of producing necrosis were related to each other.

Recently, De and Chatterje (1953) performed rabbit loop experiments to study the action of Vibrio cholerae on the intestine. De, Bhattacharya and Sarker (1956) extended the experiments to determine the pathogenicity of Escherichia cultures isolated from acute and chronic enteritis. From the results of their experiments, they suggested that the serological properties of the cultures might not be correlated with their pathogenicity for the rabbit intestine.

The authors (Namioka, Urushido and Sakazaki, 1958) carried out an experiment similar to that of De et al. using about 40 cultures isolated from transmissible gastroenteritis in pigs caused by a viral agent, and concluded that, in this case, toxic Escherichia organisms, which might have normally been harbored in the large intestine, migrated into the small intestine where they aggravated enteritis in association with the causative agent. Moreover, so far as Escherichia organisms isolated from transmissible gastroenteritis are concerned, no remarkable relationships were observed among 0 inagglutinability, hemolytic and necrotizing powers, and pathogenicity for the rabbit intestine.

Rolle and his co-workers (Rolle and Kalich, 1955; Botze, 1956) described that various toxic strains of Escherichia possessed an ability of agglutinating the sperm of the dog, while atoxic (non-pathogenic) organisms were lacking in such an ability.

Many attempts have been made, however, to differentiate the culture of pathogenic

* The virulence in this study is interpreted to include toxicity.

波岡茂郎・村田昌芳（農林省家畜衛生試験場研究第 1 部細菌第 1 研究室）

坂崎利一（国立予防衛生研究所細菌第一部） 
Escherichia organisms from that of non-pathogenic. It would be very difficult to distinguish one from the other with any known procedure, although differentiation was possible among various types of disease caused by these organisms in man and animals.

It is well known that by using some reagents the invasiveness of certain organisms is enhanced directly or indirectly and, consequently, the virulence of the organisms seems to be intensified. Nungester et al. (1936) reported that Salmonella typhosa and some other organisms, when treated with mucin, increased their virulence. Such enhancement of pathogenicity was also demonstrated with the spreading factors discovered by Duran-Reynals (1942). Chain $(1939,1940)$ described that the diffusibility of the organisms into certain tissue was accelerated when the host was administered with hyaluronidase. This effect is presumed to be due to an increase in tissue permeability which results from the enzymatic hydrolysis of hyaluronic acid and with facilitates infiltration and spread of pathogenes.

Recently, an assumption has been made on the possible presence of a wetting agent, a kind of surface activate agent, by the function of which the surface tension of tissue cells is depressed and capillary permeability increased. Consequently, this agent might facilitate the access of organisms to the tissues of their hosts. Christovao (1957) descovered that the pathogenicity of Shigella dysenteriae and Sh. Alexneri for mice was consistently increased as shown by their $\mathrm{LD}_{50} 100$ to 2,000 times as small as those of the controls. Similar results had been obtained from his preliminary experiment (Christovao, 1955) with Salmonella typhosa injected simultaneously with a wetting agent (dioctyl sodium sulfosuccinate) by the intraperitoneal route.

The authors have performed an experiment on pathogenicity of Escherichia organisms for mice treated with wetting agents, studying the virulence of the organisms, their distribution in the tissues of their host, change in body weight and histopathological findings of their host.

\section{MATERIALS AND METHODS}

Mice: Three-week-old mice of ddN strain, weighing about $14 \mathrm{~g}$, were employed. They had been bred in the National Institute of Animal Health, Tokyo, in closed breeding.

Medium: To obtain constant results, the authors used dehydrated medium of their own preparation throughout the present study. The contents of $1,000 \mathrm{cc}$ of the liquid medium were as follows.

$\begin{array}{lrr}\text { Yeast extract (Difco) } & & 5.0 \mathrm{~g} \\ \text { Peptone (Arei) } & 15.0 \mathrm{~g} \\ \text { Dextrose } & 2.5 \mathrm{~g} \\ \text { Sodium chloride } & 4.0 \mathrm{~g} \\ \text { Dipotassium phosphate } & & 4.0 \mathrm{~g} \\ & & \mathrm{pH} 7.2\end{array}$

Cultures: Twenty-eight cultures were studied. They consisted of 23 cultures of Escherichia and 5 cultures of Salmonella. The details of these cultures were as follows.

\begin{tabular}{llll}
\multicolumn{1}{c}{ Strain } & O group & Source & \multicolumn{1}{c}{ Disease produced } \\
\hline Kitasato 4 & 55 & Feces & $\begin{array}{l}\text { Epidemic infantile gastro-enteritis } \\
\text { (E. I. G. E.) }\end{array}$ \\
Kitasato 8 & 26 & Feces & E. I. G. E. \\
Kitasato 24 & 111 & Feces & E. I. G. E.. \\
Kitasato 26 & 111 & Feces & E. I. G. E. \\
Iwate & Unknown & Feces & Gastro-enteritis (child) \\
Horie & $28 \mathrm{a}, 28 \mathrm{c}$ & Feces & Dysentery (child) \\
Suzuki & 136 & Feces & Dysentery (adult)
\end{tabular}




\begin{tabular}{lcll}
\multicolumn{1}{c}{ Strain } & O group & \multicolumn{1}{c}{ Source } & \multicolumn{1}{c}{ Disease produced } \\
\hline H 5 & 78 & Heart blood & White scour of calf \\
$799-2$ & 78 & Heart blood & Typhoid-like disease of fowl \\
Kawamura & 5 & Liver & Sepsis of newborn chick \\
A-M & 4 & Liver & Coli-granulomatis of turkey \\
P 25 & 20 & Contents of & Transmissible gastro-enteritis in pigs \\
& & small intestine & (T. G. E.) \\
P 38 & & C. S. I.) & \\
P 49 & 84 & C. S. I. & T. G. E. \\
P 52 & 131 & C. S. I. & T. G. E. \\
P 4 & 98 & C. S. I. & T. G. E. \\
P 66 & 49 & C. S. I. & T. G. E. \\
P 104 & 86 & C. S. I. & T. G. E. \\
P 55 & Unknown & C. S. I. & T. G. E. \\
P 57 & 127 & Faces & Healthy pig \\
P 30 & 83 & Feces & Healthy pig \\
S. N. & 85 & Feces & Healthy pig \\
K 8 & Unknown & Feces & Healthy man \\
Salmonella potsdam & Unknown & Feces & Healthy cattle \\
Salmonella senftenberg & Feces & Gastro-enteritis (adult) \\
& Mesenteric & Healthy dog \\
Salmonella thompson & lymph node & \\
Salmonella paratyphi B & (M. L. N.) & \\
Salmonella typhi murium & M. L. N. & Healthy dog \\
& & Bile & Paratyphoid of a woman \\
& & M. L. N. & Healthy dog \\
& &
\end{tabular}

Some of the cultures studied were fresh and others had been stored under lyophilized conditions since their isolation.

Aerosol-OT* (dioctyl sodium sulfosuccinate): The molecular formula of this substance is $\mathrm{C}_{20} \mathrm{H}_{37} \mathrm{NaO}_{7} \mathrm{~S}$ and its hydrophilic lyophilic balance is about 7 . No side effect was revealed by a 4-weekold mouse which had been administered with $100 \mathrm{mg}$ of Aerosol-OT daily for 7 consecutive days by the oral route. On the other hand, when injected peritoneally with $1 \mathrm{mg}$ of Aerosol-OT, a mouse exhibited transitional perspiration, which disappeared within one hour. Aqueous solution of Aerosol-OT $(2.4 \mathrm{~g} / 1,000 \mathrm{cc})$ had no germicidal function over enteric bacteria nor any influence upon the phagocytic power of mouse macrophages. Aqueous solution of Aerosol-OT at a concentration of $2.4 \mathrm{~g}$ per $1,000 \mathrm{cc}$ was used in this study. The optimum dose of Aerosol-OT for injection was determined from the results of the preliminary experiment; all mice received intraperitoneally $0.2 \mathrm{cc}$ of the aqueous solution of Aerosol-OT (net quantity of Aerosol-OT being 0.48 $\mathrm{mg}$ ) together with the organisms. Each experimental group consisted of 6 mice.

Cultivatlon and injection of cultures: Ten loopfuls of the organism incubated at $37^{\circ} \mathrm{C}$ for 12 hours in broth were planted in $5 \mathrm{cc}$ of broth and cultivated at $37^{\circ} \mathrm{C}$ for 6 to 7 hours. Viable count of the broth culture was consistently 80 to 100 million per cc. Mice received intraperitoneally $0.2 \mathrm{cc}$ of each decimal dilution of broth culture. The value of $\mathrm{LD}_{50}$ was determined by the method of Behrens-Kärber.

Each mouse was weighed at intervals of two days. At the time of weighing, one mouse from each group was killed by chloroform-gas for bacteriological and histopathological examinations.

\section{RESULTS}

The results of the experiments are shown in Table 1. Previousely the authors (Namioka, Urushido and Sakazaki, 1958) reported that 93.3 per cent of the Escherichia culture isolated from contents of the stomach and duodenum of pigs suffering from viral transmissible gastro-enteritis had produced enteritis in the isolated intestine of the rabbit (the pathogenicity test on rabbits of De et al., 1957), while 81.1 per cent of the Esche-

* A product of the American Cyanamid Co. 
Table 1. Enhancement of virulence of Escherichia and Salmonella cultures for mice by simultaneous injection with Aerosol-OT

\begin{tabular}{|c|c|c|c|c|c|}
\hline \multicolumn{3}{|c|}{ Strain } & \multirow{2}{*}{$\begin{array}{l}\mathrm{LD}_{50}(-\log ) \\
\text { organisms } \\
\text { only }\end{array}$} & \multirow{2}{*}{$\begin{array}{l}\mathrm{LD}_{50}(-\log ) \\
\text { organisms } \\
\text { with } \\
\text { Aerosol-OT }\end{array}$} & \multirow{2}{*}{$\begin{array}{c}\text { Enhancement } \\
\text { of } \\
\text { virulence }\end{array}$} \\
\hline Source & Name & Type & & & \\
\hline \multicolumn{6}{|l|}{ Escherichia } \\
\hline \multirow{6}{*}{$\begin{array}{l}\text { Strains showing } \\
\text { positive reaction } \\
\text { in the test of De } \\
\text { et al. }\end{array}$} & P 25 & $0-20$ & 0.7 & 2.75 & $\times 112$ \\
\hline & P 38 & $0-84$ & 1.0 & 2.10 & $\times 13$ \\
\hline & P 66 & $0-86$ & 1.75 & 3.50 & $\times 56.3$ \\
\hline & P 49 & $0-131$ & 0.30 & 0.70 & $\times 2.5$ \\
\hline & $\mathrm{P} 4$ & $0-49$ & 0.50 & 0.70 & $\times 1.6$ \\
\hline & P 52 & $0-98$ & 1.50 & 1.90 & $\times 2.5$ \\
\hline \multirow{6}{*}{$\begin{array}{l}\text { Normal materials } \\
\text { from healthy } \\
\text { animals }\end{array}$} & P 57 & $0-83$ & 0.20 & 0.25 & $\times 1.13$ \\
\hline & P 30 & $0-85$ & 0.50 & 1.10 & $\times 3.99$ \\
\hline & P 104 & Unknown & 0.10 & 0.50 & $\times 2.5$ \\
\hline & S. N. & Unknown & 0.50 & 0.50 & $\times 1$ \\
\hline & K 8 & Unknown & 1.90 & 3.10 & $\times 13.2$ \\
\hline & P 55 & $0-127$ & 0.75 & 1.30 & $\times 3.55$ \\
\hline \multirow{4}{*}{$\begin{array}{l}\text { Pathological } \\
\text { materials } \\
\text { from animals }\end{array}$} & $799-2$ & $0-78$ & 1.15 & 5.25 & $\times 12,590$ \\
\hline & $\mathrm{H} 5$ & $0-78$ & 1.25 & 3.30 & $\times 112$ \\
\hline & A-M & $0-4$ & 1.50 & 2.90 & $\times 25$ \\
\hline & Kawamura & $0-5$ & 0.75 & 2.50 & $\times 63.1$ \\
\hline \multirow{7}{*}{$\begin{array}{l}\text { Pathological } \\
\text { material from } \\
\text { human beings }\end{array}$} & Horie & $0-28 \mathrm{a}, 28 \mathrm{c}$ & 0.70 & 2.20 & $\times 31.7$ \\
\hline & Kitasato 26 & $0-111$ & 0.70 & 2.30 & $\times 39.9$ \\
\hline & Kitasato 24 & $0-111$ & 0.80 & 2.20 & $\times 25$ \\
\hline & Kitasato 4 & $0-55$ & 0.90 & 1.30 & $\times 2.5$ \\
\hline & Kitasato 8 & $0-26$ & 0.50 & 1.80 & $\times 20$ \\
\hline & Iwate & Unknown & 0.50 & 2.00 & $\times 31.7$ \\
\hline & Suzuki & $0-136$ & 0.50 & 0.93 & $\times 2.7$ \\
\hline \multicolumn{6}{|l|}{ Salmonella } \\
\hline & \multicolumn{2}{|c|}{ S. typhi murium } & 5.10 & 9.00 & $\times 7,950$ \\
\hline & \multicolumn{2}{|c|}{ S. paratyphi $B$} & 1.50 & 5.50 & $\times 10,000$ \\
\hline & \multicolumn{2}{|c|}{ S. potsdam } & 0.50 & 1.00 & $\times 3.1$ \\
\hline & \multicolumn{2}{|c|}{ S. senftenberg } & 0.25 & 0.79 & $\times 3.1$ \\
\hline & \multicolumn{2}{|c|}{ S. thompson } & 0.75 & 1.20 & $\times 1.1$ \\
\hline
\end{tabular}

richia cultures isolated only from the colon of such pigs had not. Six Escherichia cultures which had shown positive reaction in the test of De et al. were inoculated into mice intraperitoneally with Aerosol-OT. Of these cultures, three ( $\mathrm{P} 25, \mathrm{P} 38$, and P 66) enhanced their pathogenicity, giving $\mathrm{LD}_{50}$ about one-hundredth as small as that of the control, while the other 3 cultures ( $\mathrm{P} 49, \mathrm{P} 4$, and $\mathrm{P}$ 52) did not enhance their own virulence. On the other hand, no remarkable difference in $\mathrm{LD}_{50}$ was observed bet- 
ween the untreated controls and the cultures $\mathrm{P} 30, \mathrm{P}$ 57, and P 104, which had been isolated from the faces of a healthy man and animals, when these cultures were inoculated intraperitoneally into mice with Aerosol-OT. In this case, general conditions of the mice injected with the organisms and Aerosol-OT recovered to normal within 24 hours, and their body weight increased rapidly after 3 days. As shown in Fig. 1, the organisms located in the liver of surviving mice disappeared, except those of culture P 55, within 5 days after the inoculation.

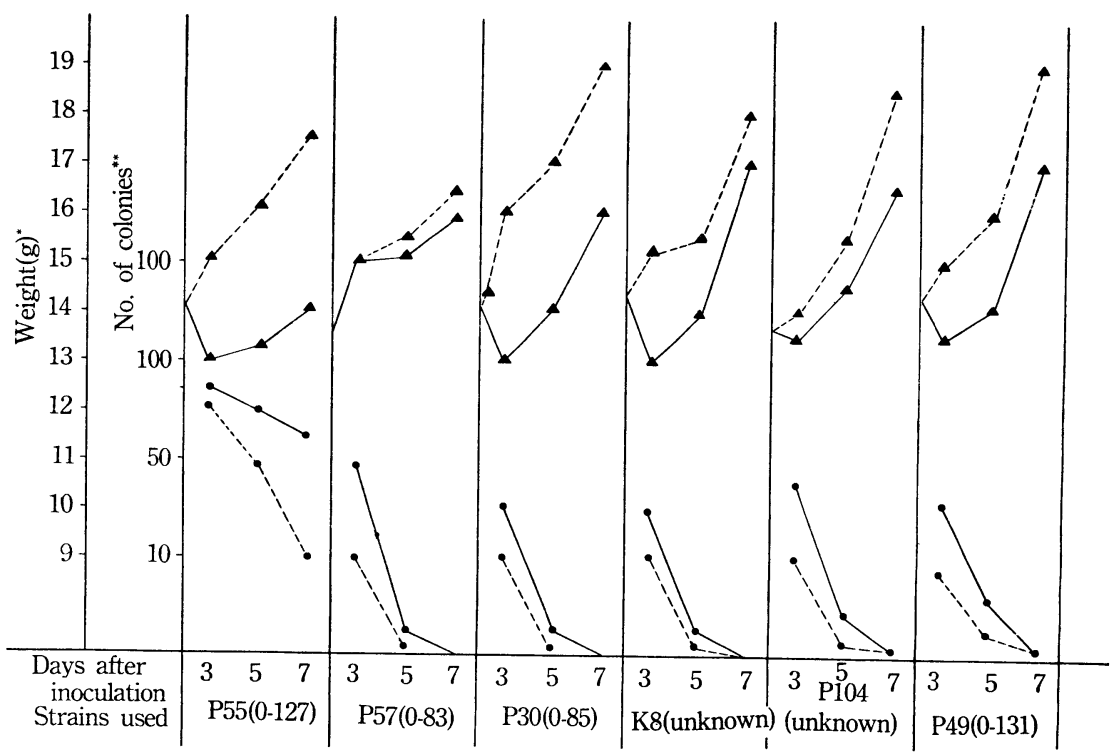

Fig. 1. Comparison of weight and distribution of organisms in liver between mice treated with Aerosol-OT and untreated controls.

Solid line: mice treated with Aerosol-OT.

Dotted line: untreated controls.

* Average weight $(\mathrm{g})$.

** Number of colonies on MacConkey agar plate by direct incubation of liver.

When Escherichia cultures isolated from pathological materials of animals involved in some infections other than transmissible gastro-enteritis were inoculated simultaneously with Aerosol-OT, they enhanced their virulence remarkably as compared with the controls (Table 1). The values of $\mathrm{LD}_{50}$ of strains $\mathrm{H} 5$ (O 78) and 779-2 (O 78), isolated from the heart blood of whith scour of the calf and typhoid-like disease of the fowl, were 100 and 10.090 times smaller than those of the controls as the results of simultaneous inoculation with Aerosol-OT. Similarly, when cultures Kawamura (O 5) and A-M (O 4), isolated from sepsis of a chick and coli-granulomatis of a turkey, respectively, were inoculated simultaneously with Aerosol-OT, these organisms exhibited an increased pathogenicity as shown by $\mathrm{LD}_{50}$ values 63.1 and 25 times, respectively, smaller than those of the controls. As indicated in Fig. 2, the weight of mice inoculated with strain 799-2 (O 78) and Aerosol-OT decreased remarkably soon after the inoculation especially after appearance of serious symptoms. Most of the mice inoculated with strain 799-2 and Aerosol-OT died within 24 to 48 hours and the remainder also died within 7 days with persistent symptoms of the first stage of infection. These mice revealed no increase in weight. Numerous organisms were recovered from the liver of surviving mice. 


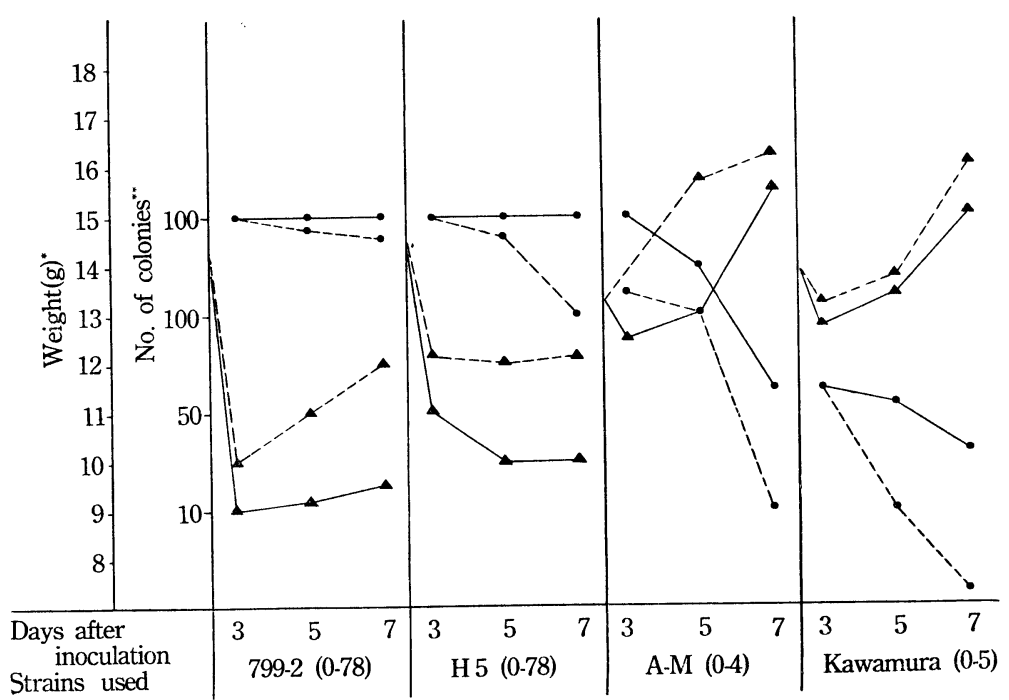

Fig. 2. Comparison of weight and distribution of organisms in liver between mice treated with Aerosol-OT and untreated controls.

Solid line: mice treated with Aerosol-OT.

Dotted line : untreated controls.

* Average weight $(\mathrm{g})$.

** Number of colonies on MacConkey agar plate by direct incubation of liver.

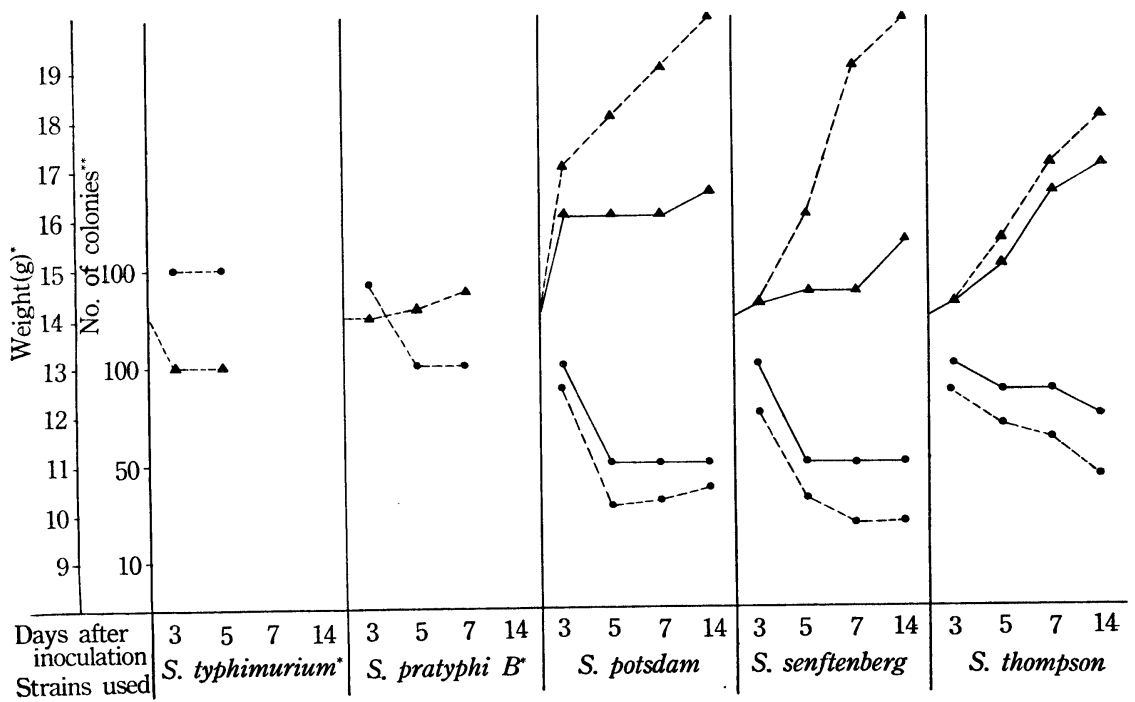

Fig. 3. Comparison of weight and distribution of organisms in liver between mice treated with Aerosol-OT and untreated controls.

Solid line: mice treated with Aerosol-OT.

Dotted line: untreated controls.

* Average weight (g).

** Number of colonies on MacConkey agar plate by direct incubation of liver.

*** All mice died within 24 hours after simultaneous inoculation with organisms and Aerosol-OT. 
In the study of Escherichia cultures isolated from epidemic infantile gastro-enteritis and focd poisoning in adults, it was shown that the enhancement of their pathogenicity due to simultaneous injection with Aerosol-OT was not so distinct as in the case of the organisms isolated from pathological materials of an animal origin. The former organisms showed $\mathrm{LD}_{50}$ values 2.5 to 40 times smaller than those of the controls.

On the other hand, similar experiments were carried out on certain Salmonella cultures. As is shown in Table $1, \mathrm{LD}_{50}$ of $S$. typhi murium for the mouse was $10^{-5}$, while it was in the order of $10^{-9}$ when the organism was inoculated with the wetting agent, mice died of primary septicemia. The $\mathrm{LD}_{50}$ of $S$. paratyphi $B$ for the mouse was about $10^{-1.5}$ showing that the virulence of this organism was lower than that of $S$. typhi murium, but it became 10,000 times smaller when the organism was inoculated with Aerosol-OT. On the contrary, S. fotsdam, S. senftenberg, and S. thompson did not enhance their virulence when inoculated with Aerosol-OT. These Salmonella organisms, however, multiplied in the liver of the mouse considerably. As indicated Fig. 3 , they remained in the liver of inoculated mice for a relatively long time, as compared with Escherichia cultures at large.

An conclusion would be brawn from the results mentioned above. Generally, there were no remarkable differences in $\mathrm{LD}_{50}$ for mice among Escherichia types, although the enhancement of pathogenicity was clearly observed in certain cultures when they were inoculated simultaneously with Aerosol-OT.

Histopathological examination was carried out on the liver of mice inoculated with various Escherichia cultures and Aerosol-OT. Generally, it seems likely that the pathological changes of the liver were more distinct in mice inoculated with organisms with their virulence enhanced by the presence of Aerosol-OT than in those inoculated with organisms in which no enhancement of pathogenicity was observed. Figs. 4 and 5 illustrate histopathological changes of the liver of mice inoculated with strains 799-2 (O 78 ) and Horie $(28 \mathrm{a}, 28 \mathrm{c})$, respectively, together with Aerosol-OT. Furthermore, Fig. 6 shows histological observations on the liver of mice receiving organisms isolated from normal materials (P 30; O 85). As is clear from these pathological changes, Escherichia cultures with their virulence enhanced by Aerosol-OT possess an ability propagating well in the liver, and severe pathological, or typhom-like, changes are caused by these organisms.

A typhom was formed in the liver by $S$. typhi murium, while no remarkable changes of the liver were observed in mice receiving $S$. potsdam and Aerosol-OT, nor in mice receiving $S$. thompson and $S$. senftenberg, as is shown in Fig. 7.

\section{DISCUSSION}

Though these is something unknown in the pharmacology of Aerosol-OT, it is to be emphasized that the wetting agent, functioning to make interfacial contact close, might facilitate access of the organism to the interior of the host tissues through liquid media, and consequently would depress capillary permeability. From this fact it may be considered that when the organism is inoculated intraperitoneally with Aerosol-OT, it invades easily capillaries or some tissue of the host, without being hampered by any influence of the peritoneal defense mechanism of phagocytes. The authors consider that the differences in pathogenicity or virulence among Escherichia cultures may be due to those in capacity of propagating in the host tissues, especially in the liver. The action of the wetting agent as described previousely may play an important role in the host in the early stage of 


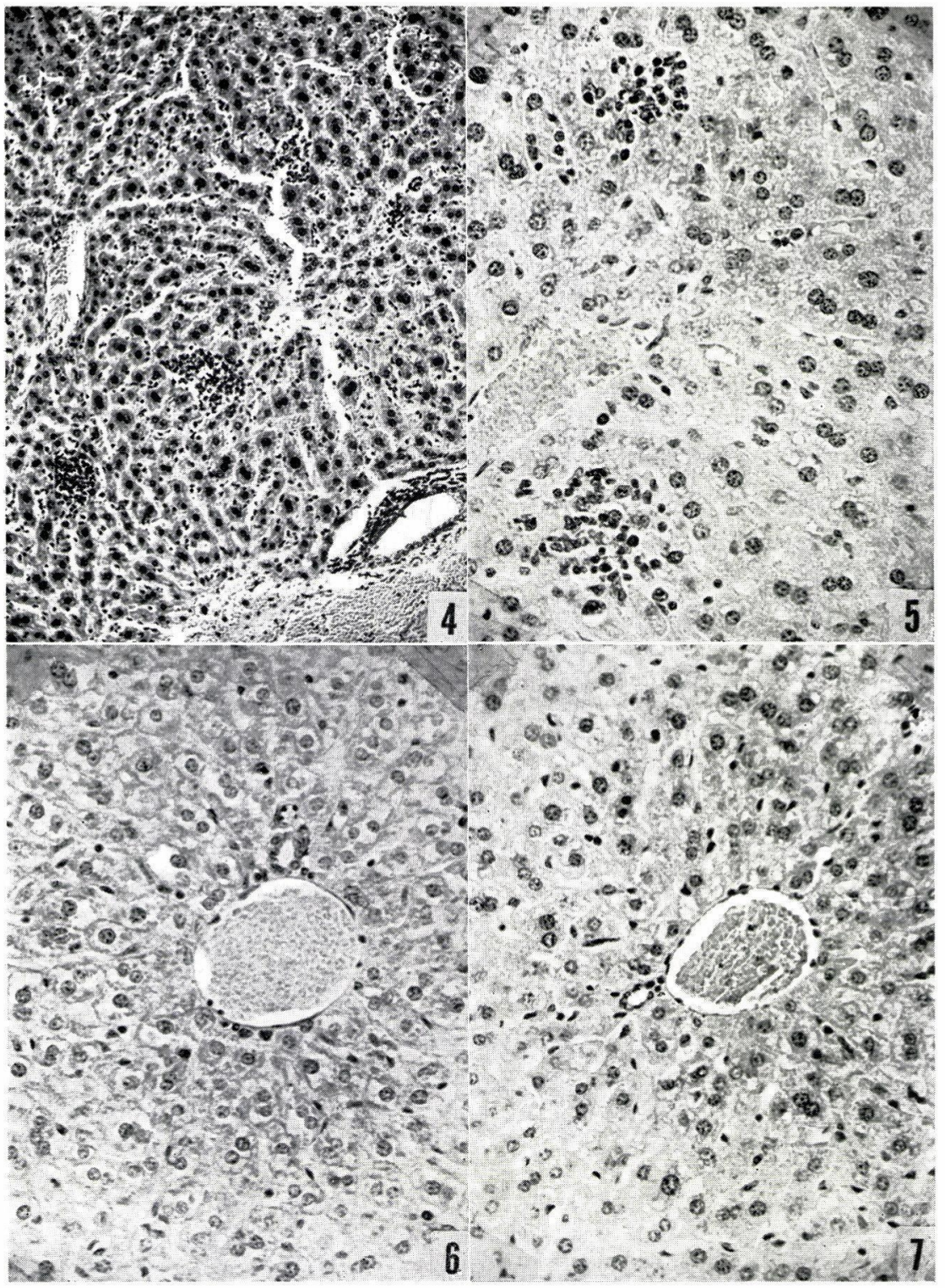

Fig. 4-7. Histopathological changes of liver of mice inoculated with Escherichia and Salmonella cultures and Aerosol-OT.

Fig. 4. Inoculated with $16 \times 10^{3}$ organisms of strain $799-2$ and killed after 7 days. Central congestion, perivascural round-cell infiltration, and typhom-like nodules are seen.

Fig. 5. Inoculated with $2 \times 10^{5}$ organisms of strain Horie and killed after 7 days. Distinct activation of RES cells, focal necrosis with nodular proliferation of round cells having light nuclei are seen.

Figs. 6 and 7 . Inoculated with $8 \times 10^{5}$ and $8 \times 10^{4}$ organisms of strain $\mathrm{P} 30$ and $S$. potsdam, respectively, and killed after 7 days. In both figures, no noticeable changes are shown, except slight swelling of sinusoidal and endotherial cells. 
infection by the organism. Miles (1957) observed a relationship between intradermal inflammation and capillary permeability. In his experiment, local inflummation with various pathogens was aggravated by the inculation of the liquid (sodium polyanethol sulfonate) which made the capillary permeability changeable.

There is no doubt that some Escherichia organisms possess a relatively high pathogenicity. However, since the spectra of pathogenicity of Escherichia cultures have a very wide range, the category of their pathogenicity, virulence, or toxicity cannot be scrutinized in a simple manner. In the authors' experiments (Namioka, Urushido and Sakazaki 1958), the pathogenicity (toxicity) of Escherichia culture could not essentially be elucidated by merely investigating the hemolytic and necrotizing powers of the organism. With regard to problems on discriminating pathogenic Escherichia cultures from nonpathogenic ones, the authors (Namioka, Urushido and Sakazaki, 1958) obtained rather definite results by using the test of De et al. (1957). However, the pathogenicity of Escherichia cultures which had shown positive reaction in De's test would be divided into several grades by using Aerosol-OT. The $\mathrm{LD}_{50}$ values for mice of the cultures of one group were less than $10^{-2}$ when inoculated with Aerosol-OT, while those of the cultures of the other group under-went no change by the simultaneous inoculation with Aerosol-OT. On the other hand, consideration has been given to the interesting results obtained by Sakazaki, Nakaya, Kosakai and Namioka (unpublished data). According to them, some of the Escherichia cultures which were regarded as causative agents of food poisoning did not change their own pathogenicity (virulence) for mice when inoculated with Aerosol-OT, but when inoculated with the wetting agent, Escherichia cultures $(\mathrm{O} 4, \mathrm{O} 25, \mathrm{O} 18$, and $\mathrm{O} 8$ ) isolated from Shigella-free dysentery changed their $\mathrm{LD}_{50}$ values for mice from $10^{-0.5}$ to $10^{-3}$, from $10^{-0.5}$ to $10^{-2}$, from $10^{-1}$ to $10^{-2.5}$, and from $10^{-1}$ to $10^{-3.1}$, respectively.

The results mentioned above are similar to those presented by Christovao (1957). He reported that the pathogenicity for mice of cultures of Sh. dysenteriae and Sh. Alexneri was enhanced by the simultaneous inoculation with the wetting agent (Deseresol-OT). These findings would be very important for the clarification of certain characteristics of the pathogenicity of Escherichia coli isolated from a case of clinical dysentery free from Shigella. Further exploration should be undertaken on the respects mentioned above in order to understand the behaviors of Escherichia cultures of different pathogenicities.

\section{SUMMARY}

The authors carried out an experiment on the pathogenicity of Escherichia cultures for mice treated with the wetting agent dioctyl sodium sulfosuccinate (Aerosol-OT). The following results were obtained.

1. The pathogenicity of Escherichia cultures which had shown positive reaction in the test of De et al. was categorized into several grades by using Aerosol-OT.

2. The $\mathrm{LD}_{50}$ values of strains $\mathrm{H} 5(\mathrm{O} 78)$ and 799-2 (O 78) isolated from the heart blood of white scours of the calf and the heart blood of typhoid-like disease of the fowl, respectively, were 100 and 10,000 times smaller than that of the controls when the organism and Aerosol-OT were inoculated simultaneously.

3. Cultures isolated from epidemic infantile gastro-enteritis and food poisoning did not enhance their pathogenicity, so much as controls, when inoculated simultaneously with Aerosol-OT.

4. Salmonella potsdam, S. senftenberg, and S. thompson did not enhance their virulence when inoculated with Aerosol-OT. 
5. The pathological changes of the liver were severer in mice receiving organisms with their virulence enhanced by the simultaneous injection of Aerosol-OT than in those inoculated with organisms whose pathogenicity showed no enhancement by the similar injection.

The authors wish to thank Dr. H. Hiroki of the Kitasato Institute for Infectious Diseases, Tokyo, for his help in acquiring cultures.

\section{REFERENCES}

BotZE, F. (1956): Experimentelle Untersuchungen über spermaagglutinierende und toxische Eigenschaften der Kolikeime. Habilitationsschrift, Institut Tierhygiene der Tierärztlichen Fakultät München.

Chain, E. \& Duthie, E. S. (1939): A mucolytic enzyme in testis extracts. Nature, 144, 977-978.

Chain, E. \& Duthie, E. S. (1940): Identity of hyaluronidase and spreading factor. Brit. J. Exper. Path., 21, 324-338.

ChristovaO, D. DE A. (1955): Arg. Fac. Hig. Saude. Pub., 9, 149. Cited in Christovao, D. de A. (1957): Proc. Soc. Exper. Biol \& Med., 94, 724-725.

ChristovaO, D. DE A. (1957): Enhancement of pathogenicity of Enterobacteriaceae for mice by wetting agents. Proc. Soc. Exper. Biol. \& Med., 94, 724-725.

DE, S. N. \& ChatterJe, D. N. (1953): An experimental study of the mechanism of action of Vibrio cholerae on the intestinal mucous membrane. J. Path. \& Bact., 66, 559-562.

DE, S. N., Bhattacharya, K. \& SARker, J. K. (1956): A study of the pathogenicity of strains of Bacterium coli from acute and chronic enteritis. J. Path. \& Bact., 71, 201-209.

Duran-Reynals, F. (1942) : Bact. Rev., 6, 197. Cited in Christovao, D. DE A. (1957): Proc. Soc. Exper. Biol. \& Med., 94, 724-725.

EWERTSEN, H. W. (1946): Dyreexperimentelle undersgelser over colibacillernes pathogenitet og effekten of coliserum. Nyt Nordisk Forlag, Arnold Busck, Copenhagen.

MiLES, A. A. (1957) : Local defences against infection and their relation to the general reticuloendothelial defences. Physio-pathology of the reteculo-endothelial system. A symposium, 188-203, Charles C. Thomas Publisher, Springfield, Illinois.

NAMIOKA, S., URUSHIDO, M. \& SAKAZAKI, R. (1958) : Escherichia coli isolated from transmissible gastro-enteritis in pigs. Jap. J. M. Sc. \& Biol., 11, 141-151.

Nungester, W. J., Jourdonais, L. F. \& Wolf, A. A. (1936) : The effect of mucin on infections by bacteria. J. Infect. Dis., 59, 11-21.

Rolle, M. \& KAlich, J. (1955) : Pathogenese der Fleischvergiftung. Zentralbl. Bakt. I. Orig., $164,86-88$.

SJOSTEDT, S. (1946): Pathogenicity of certain serological types of B. coli. Gleerupska UnivBokhandeln, Lund. 